\title{
Statistical testing of input factors in the carbonation of brine impacted fly ash
}

\author{
MURIITHI N. GRACE ${ }^{1}$, GITARI M. WILSON ${ }^{2}$ and PETRIK F. LESLIE ${ }^{1}$ \\ ${ }^{1}$ Environmental and Nano Sciences Group, University of the Western Cape, South Africa \\ ${ }^{2}$ Department of Ecology and Resource Management, School of Environmental studies, University of Venda, South \\ Africa. \\ Address correspondence to Muriithi N. Grace, Environmental and Nano Sciences Group, University of the Western \\ Cape, South Africa; E-mail: gmuriithi@uwc.ac.za \\ Received April 7, 2011
}

A D-optimal design was applied in the study of input factors: temperature, pressure, solid/liquid (S/L) ratio and particle size and their influence on the carbonation of brine impacted fly ash (FA) determined. Both temperature and pressure were at two levels $\left(30^{\circ} \mathrm{C}\right.$ and $90^{\circ} \mathrm{C} ; 1 \mathrm{Mpa}$ and $\left.4 \mathrm{Mpa}\right), \mathrm{S} / \mathrm{L}$ ratio was at three levels (0.1, 0.5 and 1 ) while particle size was at 4 levels (bulk ash, $<20 \mu \mathrm{m}, 20 \mu \mathrm{m}-150 \mu \mathrm{m}$ and $>150 \mu \mathrm{m}$ ). Pressure was observed to have a slight influence on the $\% \mathrm{CaCO}_{3}$ yield while higher temperatures led to higher percentage $\mathrm{CaCO}_{3}$ yield. The particle size range of $20 \mu \mathrm{m}-150 \mu \mathrm{m}$ enhanced the degree of carbonation of the fly ash/brine slurries. This was closely followed by the bulk ash while the $>150 \mu \mathrm{m}$ particle fraction had the least influence on the $\% \mathrm{CaCO}_{3}$. The effect of $\mathrm{S} / \mathrm{L}$ ratio was temperature dependent. At low temperature, the $\mathrm{S} / \mathrm{L}$ ratio of 1 resulted in the highest $\% \mathrm{CaCO}_{3}$ formation while at high temperature, the ratio of 0.5 resulted in the highest percentage $\mathrm{CaCO}_{3}$ formation. Overall the two most important factors in the carbonation of FA and brine were found to be particle size and temperature.

Keywords: Design of experiments, D-optimal design, fly ash, brine, mineral carbonation, sequestration, ANOVA, chittick test.

\section{Introduction}

Coal combustion provides $40 \%$ of the world's energy needs. ${ }^{[1]}$ This figure is projected to increase due to the in- creased demand for electricity due to industrialization as well as population growth and the availability of large coal reserves in different parts of the world. [2,3] However, the combustion of coal leads to the generation of coal utiliza- tion by-products (CUB's) such as $\mathrm{CO}_{2}$, and $\mathrm{N}_{2} \mathrm{O}$ as gaseous emissions, solid wastes such as $\mathrm{FA}$, flue gas desulphuriza- tion products (FGD) and waste waters in form of brine. The gaseous emissions contribute to the global warming effect, while waste FA, brines, and FGD are possible soil and water pollutants. Annually the electricity generating industry in South Africa produces over 218 million tons of $\mathrm{CO}_{2}{ }^{[4]}$ with over $30 \mathrm{Mt} / \mathrm{y}$ of FA and vast amounts of waste brines.

Co-utilization of FA and brine to sequester $\mathrm{CO}_{2}$ in the form of mineral carbonates would thus be beneficial to the power generating industry for emission reduction purposes and benign utilization of the waste products. The need to develop a statistical theory for designing experiments stems from the inherent variability of experimental results. [5] The "design of experiments" (DOE) soft- ware allows the design of a protocol that considers all the factors optimizing on the outcome of the response factor. The classical method of experimental optimization involves changing one factor at a time while holding other factors constant. [6] This method however requires a large number of experiments to illustrate the effect of individual factors. In addition it omits the effect of interactions of various factors. [7] Use of statistical methods, however, helps to select important factors from a large number of factors and the interactions between important factors can be easily understood. 
The D-optimal criterion, one of the several optimalities, was developed to select design points in a way that minimizes the variance associated with the estimates of specified model coefficients. The D-optimal factorial design is designed for use with categorical factors as an alternative to the general factorial design option. Although the general factorial design builder may produce designs with more runs than one is willing to run, the D-optimal design on the other hand chooses an ideal subset of all possible combinations, based on the specified model. ${ }^{[8]}$ The objective of this study was to study the application of statistical analysis in the factors influencing carbonation. The factors considered were particle size, temperature, pressure and $\mathrm{S} / \mathrm{L}$ ratio.

Table 1. Design generated by Design of Experiments (DOE).

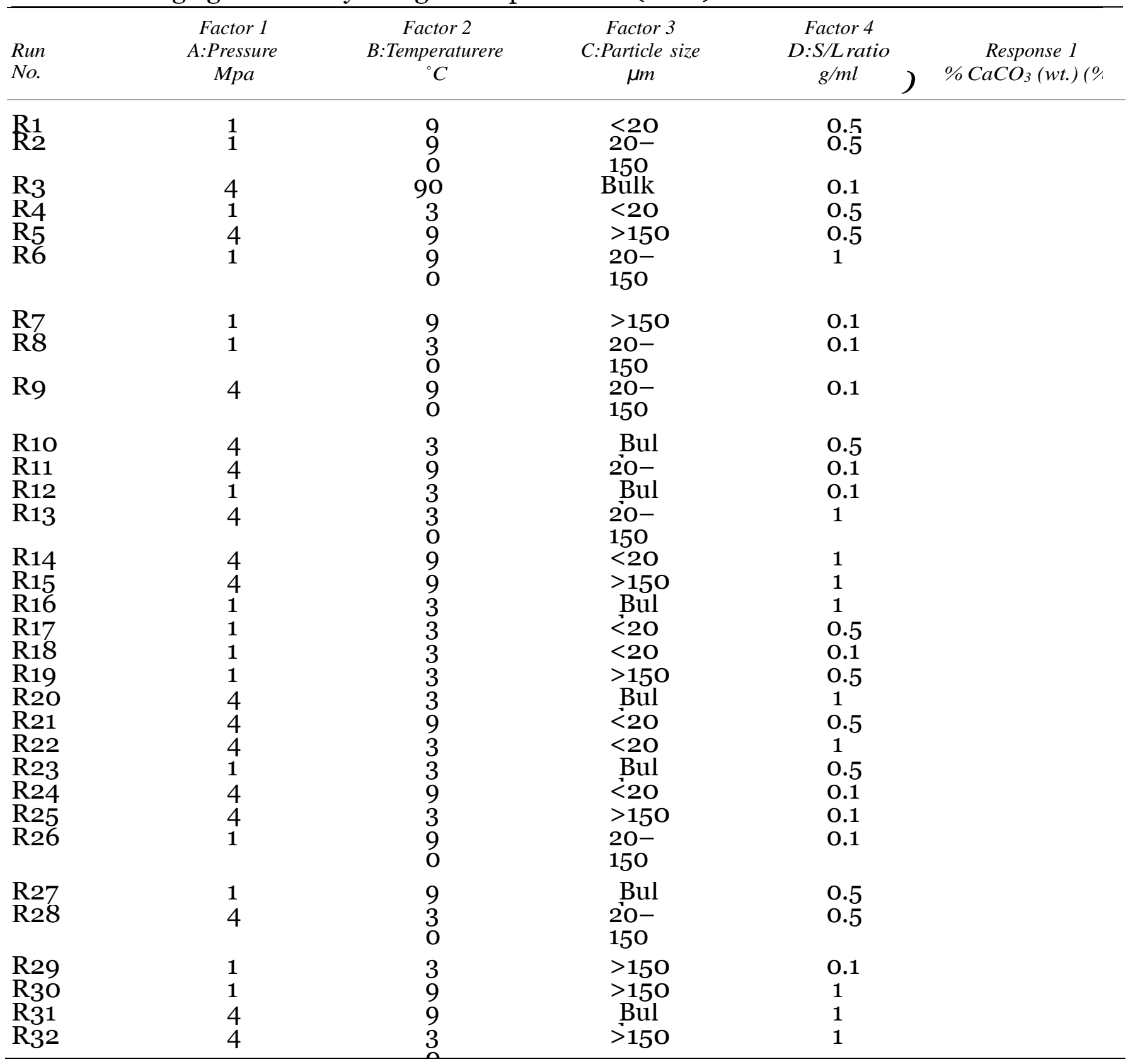




\section{Materials and methods}

\section{D-optimal design}

The input factors considered were particle size, S/L ratio, temperature and pressure while percent $\mathrm{CaCO}_{3}$ was the output factor. Both temperature and pressure were at 2 levels $\left(30^{\circ} \mathrm{C}\right.$ and $90^{\circ} \mathrm{C} ; 1 \mathrm{Mpa}$ and $\left.4 \mathrm{Mpa}\right), \mathrm{S} / \mathrm{L}$ ratio was at three levels (0.1, 0.5 and 1), yet particle size was at 4 levels (bulk ash, $<20 \mu \mathrm{m}, 20 \mu \mathrm{m}-150 \mu \mathrm{m}$ and $>150 \mu \mathrm{m}$ ). The design can therefore be referred to as a $4 \times 3 \times 2^{2}$, which simply translates to 1 factor at 4 levels, 1 factor at 3 levels and 2 factors at 2 levels each. Table 1 shows the generated design using Design-Expert 7.1.

\section{Carbonation experiments}

The carbonation reactions were carried out in a stainless steel autoclave reactor with a 6oo ml volume capacity. The brine and FA were contained in a Teflon cup that was immersed in the steel jacket. A photo of the reactor setup is shown in Figure 1.

The dispersion (brine + FA at the required S/L ratio) was placed inside the Teflon cup in the pressure vessel and closed. The reactor was then placed in the heater and thermocouple, magnetic stirrer drive system, and water coolant supply controlled by a solenoid valve put in place. The gas supply connection for the $\mathrm{CO}_{2}$ feed line was then attached. The system was purged twice with $\mathrm{CO}_{2}$ at $0.05 \mathrm{Mpa}$ to ensure that all the air was expelled and heating of the system began. When the specified temperature was reached, $\mathrm{CO}_{2}$ (technical grade) was charged into the reactor to achieve the specified reaction pressure. The brine/FA/CO2 mixture was then stirred at 600 rpm for 2 hours to prevent any settling of solids during the carbonation experiments. After 2 hours the reactor was removed from the heating system and quenched in cold water as well as depressurized for 15 minutes.

The reactor was then disassembled, and the solid product was separated by centrifugation (30 minutes at $6000 \mathrm{rpm}$ ), thereafter the supernatant solutions were decanted. Finally, the solid product was dried in a vacuum oven for 8 hrs at $90^{\circ} \mathrm{C}$. The supernatant solutions were filtered through a $0.2 \mu \mathrm{m}$ pore membrane. The filtered solutions for cation analysis were immediately acidified to $\mathrm{pH}<2$ while those for anion analysis were stored as they were, i.e., without acidification. The samples were refrigerated at $4{ }^{\circ} \mathrm{C}$ until analysis.

\section{Brine and FA characterization}

The FA and brine samples used were collected from coal burning power plants in Mpumalanga province of South Africa. Morphological analysis was done by Scanning Electron Microscopy (SEM) using a Hitachi X-650 Scanning Electron Microanalyser equipped with a CDU-lead detector at $25 \mathrm{kV}$ and a tungsten filament. Crystalline phases present in the FA were determined by X-Ray Diffraction Spectroscopy (XRD) using a Bruker AXSD8 Advance diffractometer coupled with a $\mathrm{Cu}-\mathrm{K} \alpha$ radiation at $40 \mathrm{kV}$ and $40 \mathrm{~mA}$ with a PSD Lynx-Eye, Si-strip detector at $0.03^{\circ} / 2 \theta$ step from $12^{\circ}-80^{\circ}$ and 3 seconds counting time. Elemental analysis was done by XRF using a Philips PW 1480 X-ray spectrometer fitted with a Cr tube and five analyzing crystals namely LIF 200, LIF 220, GE, PE and PX at $40 \mathrm{kV}$ and $50 \mathrm{~mA}$ tube operating conditions. Chittick tests were carried out to determine the percentage of $\mathrm{CaCO}_{3}$ in the carbonated FA by reacting $1.70 \mathrm{~g}$ of the carbonated FA with $20 \mathrm{ml}$ of $6 \mathrm{~N} \mathrm{HCl}$ and recording the amount of $\mathrm{CO}_{2}$ evolved by reading the displacement of the reservoir fluid. Anions present in the brine as well as the carbonation leachates were analyzed with an Ion Pac AS14A column and AG14-4 mm guard column Ion Chromatograph (IC). Major cations were analyzed using a 
Varian radial ICP- AES while trace cations were done on an Agilent 750oce ICP-MS using High Matrix Introduction (HMI) accessory and He as collision gas.

Table 2. XRF analysis results for major and minor elements given as oxides in \% w/w for fresh FA (Muriithi et al.[12]).

\begin{tabular}{|c|c|c|c|c|c|c|c|c|c|c|c|c|}
\hline $\begin{array}{l}\text { Majo } \\
\text { rs }\end{array}$ & Bulk & $\begin{array}{l}>15 \\
O\end{array}$ & $\begin{array}{l}150 \\
\mu m-\end{array}$ & $\begin{array}{l}106 \\
\mu m-\end{array}$ & $\begin{array}{l}90 \\
\mu m-\end{array}$ & $\begin{array}{l}75 \\
\mu m-\end{array}$ & $\begin{array}{l}63 \\
\mu m-\end{array}$ & $\begin{array}{l}53 \\
\mu m-\end{array}$ & $\begin{array}{l}45 \\
\mu m-\end{array}$ & $\begin{array}{l}32 \\
\mu m-\end{array}$ & $\begin{array}{l}25 \\
\mu m-\end{array}$ & $<2 O$ \\
\hline $\begin{array}{l}\mathrm{SiO}_{2} \\
\mathrm{TiO}_{2}\end{array}$ & $\begin{array}{c}51.22 \\
1.548\end{array}$ & $\begin{array}{r}42.45 \\
0.97\end{array}$ & $\begin{array}{r}50.64 \\
1.214\end{array}$ & $\begin{array}{r}51.770 \\
1.333\end{array}$ & $\begin{array}{c}52.41 \\
1.514\end{array}$ & $\begin{array}{r}52.66 \\
1.58\end{array}$ & $\begin{array}{r}51.40 \\
1.616\end{array}$ & $\begin{array}{c}52.64 \\
1.63\end{array}$ & $\begin{array}{r}52.37 \\
1.655\end{array}$ & $\begin{array}{r}52.70 \\
1.68\end{array}$ & $\begin{array}{c}52.76 \\
1.69\end{array}$ & $\begin{array}{r}51.11 \\
1.84\end{array}$ \\
\hline $\mathrm{Al}_{2} \mathrm{O}_{3}$ & 26.00 & 17.96 & 22.03 & 24.05 & 25.27 & 25.97 & 27.22 & 26.35 & 27.35 & 26.55 & 27.35 & 28.51 \\
\hline $\mathrm{Fe}_{2} \mathrm{O}_{3}$ & 2.43 & 1.98 & 3.47 & 2.62 & 2.75 & 2.42 & 2.419 & 2.28 & 2.39 & 2.24 & 2.24 & 2.57 \\
\hline $\mathrm{Mñ} \mathrm{O}^{\circ}$ & 0.06 & 0.04 & 0.05 & ô.06 & 0.06 & 06.06 & 0.06 & 0.06 & 0.05 & 0.06 & 0.06 & 0.06 \\
\hline $\mathrm{MgO}$ & 2.43 & 1.66 & 2.34 & 2.513 & 2.714 & 2.53 & 2.56 & 2.451 & 2.49 & 2.48 & 2.47 & 2.62 \\
\hline $\mathrm{CaO}$ & 9.19 & 5.89 & 9.01 & 9.671 & 10.28 & 9.48 & 9.591 & 9.261 & 9.129 & 8.76 & 8.49 & 8.63 \\
\hline $\mathrm{Na}_{2} \mathrm{O}$ & Ô.45 & 0.14 & 0.28 & 0.28 & 0.35 & 0.38 & 0.38 & 0.46 & 0.53 & 0.58 & ô.55 & 0.68 \\
\hline $\mathrm{K}_{2} \mathrm{O}$ & 0.78 & 0.65 & 0.77 & 0.74 & 0.76 & 0.77 & 0.78 & 06.79 & 0.81 & 0.82 & 0ิ.82 & 0ิ.87 \\
\hline $\mathrm{P}_{2} \mathrm{O}_{5}$ & 0.69 & 0.43 & 0.54 & 0.576 & 0ิ.69 & Oิ.71 & 0.74 & 0.75 & 0.77 & 0.781 & 0.77 & 0.87 \\
\hline $\mathrm{SO}_{3}$ & Ô.35 & 0.36 & 0.26 & 0.26 & 0.30 & Ô.351 & 0.317 & 0.36 & 0.37 & 0.37 & 0.38 & Ô.39 \\
\hline $\mathrm{Cr}_{2} \mathrm{O}_{3}$ & $\begin{array}{l}\text { Ô.03 } \\
3\end{array}$ & $\begin{array}{l}0.02 \\
2\end{array}$ & $\begin{array}{l}0.02 \\
9\end{array}$ & 0.031 & $\begin{array}{l}0.03 \\
3\end{array}$ & $\begin{array}{l}0.03 \\
4\end{array}$ & $\frac{0.03}{6}$ & $\begin{array}{l}\text { Ô.04 } \\
\text { O }\end{array}$ & $\begin{array}{l}0.03 \\
8\end{array}$ & $\begin{array}{l}0.04 \\
0\end{array}$ & $\begin{array}{l}0.04 \\
1\end{array}$ & $\begin{array}{l}0.04 \\
1\end{array}$ \\
\hline
\end{tabular}

\section{Results and discussions}

\section{Characterization of raw FA and brine}

The fractionated, pre-carbonated FA was characterized chemically using XRF in order to quantify major, minor and

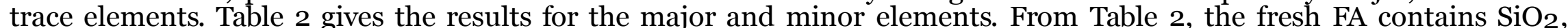
$\mathrm{Al}_{2} \mathrm{O}_{3}, \mathrm{Fe}_{2} \mathrm{O}_{3}$ and $\mathrm{CaO}$ as the major oxides. The ash can therefore be classified as class $\mathrm{F}$ since the sum percentage composition of $\mathrm{SiO}_{2}, \mathrm{Al}_{2} \mathrm{O}_{3}$ and $\mathrm{Fe}_{2} \mathrm{O}_{3}$ is greater than $70 \%$ according to the American Society for Testing and Materials (ASTM). .9] Furthermore, the CaO content is lower than $10 \%$, which is also a grading criterion for class $\mathrm{F}$ FA. $\mathrm{CaO}$ in FA is present as free lime and embedded in glassy spheres.

Usually the $\mathrm{CaO}$ content increases with decreasing particle size. However, the $\mathrm{CaO}$ content can vary due to formatiop of glassy spheres from free lime and alumino silicate melt or the reaction of free lime with $\mathrm{SO}_{2}$ via $\mathrm{CaSO}_{3}$ to anhydrite. $\mathrm{CO}_{3}$ Bearing in mind that glassy spheres are the most important $\mathrm{Al}_{2} \mathrm{O}_{3}$ bearing mineral species, $\mathrm{Al}_{2} \mathrm{O}_{3}$ content of size fractions is an indicator of the amount of glassy spheres in FA. [10] An increasing trend with decreasing particle size is clearly visible for $\mathrm{Al}_{2} \mathrm{O}_{3}$, while for the lime content the $75^{-90} \mu \mathrm{m}$ fraction has the highest lime content. Table 3 gives the ion concentrations in brine.

The brine solutions can be classified as $\mathrm{NaSO}_{4}$ waters as these are the main ions present. Other significant ions include $\mathrm{Ca}, \mathrm{K}, \mathrm{Mg}$ and $\mathrm{Cl}$ with trace quantities of $\mathrm{NO}_{3}, \mathrm{PO}_{4}, \mathrm{Al}$, As, $\mathrm{Ba}, \mathrm{Cd}$, $\mathrm{Co}, \mathrm{Cr}, \mathrm{Cu}, \mathrm{Fe}, \mathrm{Mn}, \mathrm{Mo}, \mathrm{Ni}, \mathrm{Pb}, \mathrm{Se}, \mathrm{Sr}, \mathrm{V}$ 
and $\mathrm{Zn}$. This has been reported elsewhere. ${ }^{[11]}$

Morphological analysis showed evidence of transformation from smooth spherical particles to "cubic-like" structures of calcite as is reported elsewhere. ${ }^{[12]}$ Furthermore, XRD confirmed presence of calcite in the carbonated ash, and lime fraction was present in the un-carbonated ash. ${ }^{[12]}$

Table 3. Brine solution concentrations (Muriithi et al.[12]).

\begin{tabular}{lc}
\hline Species & RO brine $(p p m)$ \\
\hline $\mathrm{K}$ & $104.1 \pm 0.31$ \\
$\mathrm{Al}$ & $0.044 \pm 0.06$ \\
$\mathrm{As}$ & 0.007 \\
$\mathrm{Ca}$ & $101.76 \pm 0.15$ \\
$\mathrm{Co}$ & $0.015 \pm 0.01$ \\
$\mathrm{Cr}$ & $0.014 \pm 0.01$ \\
$\mathrm{Cu}$ & $0.067 \pm 0.02$ \\
$\mathrm{Fe}$ & $0.051 \pm 0.01$ \\
$\mathrm{Mg}$ & $158.73 \pm 1.24$ \\
$\mathrm{Mn}$ & $0.082 \pm 0.03$ \\
$\mathrm{Mo}$ & $0.039 \pm 0.01$ \\
$\mathrm{Na}$ & $4315 \pm 2.18$ \\
$\mathrm{Ni}$ & $0.116 \pm 0.01$ \\
$\mathrm{Se}$ & 0.004 \\
$\mathrm{Sr}$ & $3.030 \pm 0.11$ \\
$\mathrm{~V}$ & $0.016 \pm 0.01$ \\
$\mathrm{Zn}$ & $0.100 \pm 0.01$ \\
$\mathrm{Cl}$ & $2036 \pm 3.26$ \\
$\mathrm{SO} 4$ & $9488 \pm 2.22$ \\
$\mathrm{NO} 3$ & $8.565 \pm 0.61$ \\
\hline
\end{tabular}

\section{Statistical analysis}

After putting in the input factors (pressure, temperature, particle size and S/L ratio at their different levels) and the response factor in this case \% $\mathrm{CaCO}_{3}$ yield, the software generated a summary of the model (Table 4), which describes the type of design chosen, number of runs generated, the various factors, their names, units used, type of factors (in this case, categorical), number of levels of each factor ( 2 for temperature and pressure, 3 for S/L ratio and 4 for particle size). Categorical factors are factors for which the levels cannot be arranged in order of magnitude. ${ }^{5}$. The focus was on the relationship of $\% \mathrm{CaCO}_{3}$ with varying levels of the input factors (temperature, pressure, particle size and $\mathrm{S} / \mathrm{L}$ ratio). Table 4 gives the design summary as generated using the Design Expert software.

Analysis of the post-carbonation solid residues carried out by quantitative XRD and chittick tests gave the following 
results (Table 5). Runs R15, R30 and R32 could not be performed due to the formation of thick slurry that could not be agitated. The above three runs were using the $>150 \mu \mathrm{m}$ ash fraction at an S/L ratio of 1 . Thus, these runs were not considered in the statistical analysis. According to results obtained from chittick tests, Run R31, which was carried out at $4 \mathrm{Mpa}, 90^{\circ} \mathrm{C}, \mathrm{S} / \mathrm{L}$ ratio of 1 using bulk ash, gave the highest percentage $\mathrm{CaCO}_{3}$ yield of $6.5 \%$ while Run R29, carried out at $30^{\circ} \mathrm{C}, 1 \mathrm{Mpa},>150 \mu \mathrm{m}$ at an S/L ratio of 0.1 gave the lowest percentage $\mathrm{CaCO}_{3}$ yield of $2.75 \%$. On the other hand in XRD quantification, Run $\mathrm{R} 2$ carried out at $1 \mathrm{Mpa}, 90^{\circ} \mathrm{C}, 20 \mu \mathrm{m}-150 \mu \mathrm{m}$ at a S/L ratio of $0.5 \mathrm{resulted}$ in the highest percentage $\mathrm{CaCO}_{3}$ yield of $8.14 \%$, yet Run $\mathrm{R} 25$ carried out at $4 \mathrm{Mpa}, 3 \mathrm{O}^{\circ} \mathrm{C},>150 \mu \mathrm{m}$ at a $\mathrm{S} / \mathrm{L}$ ratio of 0.1 gave the lowest percentage $\mathrm{CaCO}_{3}$ yield of $0.77 \%$. Statistical testing (both student t-test and concordance correlation coefficient) indicated that chittick tests were a better estimate of the $\% \mathrm{CaCO}_{3}$ in comparison to quantitative XRD. Furthermore, XRD only detects the crystalline phase and some $\mathrm{CO}_{2}$ might have gone to the amorphous phase which XRD cannot detect. Chittick tests being a form of titration are expected to release all the encapsulated $\mathrm{CO}_{2}$ within the time limit of the experiment in addition to using a high concentration of the acid $(6 \mathrm{~N} \mathrm{HCl})$. The results obtained using the chittick tests were thus applied in the DOE to interpret the data.

\section{Factor effect estimation}

Estimation of factor effects is done by evaluating the percentage contribution of each input factor (namely temperature, pressure, S/L ratio and particle size) as well as the interactions of these input factors. The percentage contribution determines which terms are larger contributors than others. To evaluate the contribution of various effects, a tentative percentage contribution of each model term to the total sum of squares is generated by the software as given in Table 6 . Table 7 gives the contribution of the main effects and the interactions arising thereof.

The sum of squares (SS) for a term is the amount of in- formation that can be attributed to the term as it changes. [8] Model terms are all the terms that are included in making the model. Aliased factors on the other hand are factors that cannot be uniquely estimated and thus their estimated effect is the linear combination of all the aliased terms. For instance, aliased "ABC" term means A is aliased within B which is aliased within C and the estimate of ABC is there- fore a linear combination of $\mathrm{A}, \mathrm{B}$ and $\mathrm{C}$. On the other hand, the $F$-value acts as a test for comparing the model variance with residual (error) variance. The percentage contribution can be used to estimate the importance of each model term. Factors with considerable contribution were the main effects of A (pressure), B (temperature), C (particle size), D (S/L ratio); interactions of $\mathrm{BC}$ and $\mathrm{BD}$. These factors were thus used to test the model significance using analysis of variance (ANOVA).

\section{Estimation of model significance}

To determine the significance of the model as well as the factor effects, ANOVA is carried out on the model. ANOVA has two main functions, first, it provides a subdivision of the total variation between experimental units into separate components, each component representing a different source of variation, thus the relative importance of the different sources can be assessed. Second, it gives an estimate of the underlying variation between units which provides a basis for inferences about the effects of the applied treatments. ${ }^{[5]}$ The ANOVA analysis for the chosen model is given in Table 7.

Table 4. Design summary. 


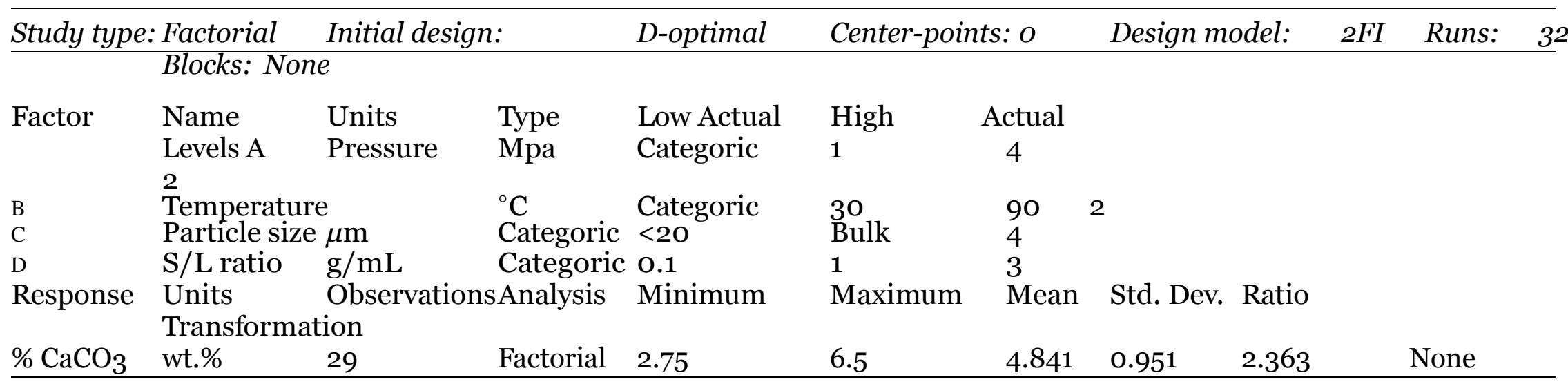


Table 5. Statistically designed experiments showing the input factors and the response factor as determined by chittick tests and quantitative XRD $(<150=20-150 \mu \mathrm{m}$ particle size range $)$.

\begin{tabular}{|c|c|c|c|c|c|c|}
\hline кun no. & $\begin{array}{c}\text { Factor } 1 \\
\text { A:Pressure } \\
\text { (Mnal }\end{array}$ & 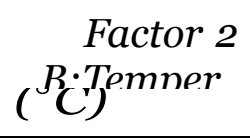 & $\begin{array}{l}\text { Factor } 3 \\
\text { C.P(rticle } \\
(\mu)\end{array}$ & $\begin{array}{l}\text { Factor } \\
1 \text { D: S S II })\end{array}$ & $\begin{array}{l}\text { Chittick } \\
\% \text { tost }\end{array}$ & 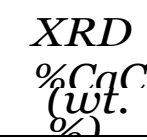 \\
\hline $\begin{array}{l}\mathrm{R} 1 \\
\mathrm{R} \text { ? }\end{array}$ & 1 & 99 & $<2$ & O. & 4.9 & 4.25 \\
\hline $\mathrm{R}_{3}$ & $\begin{array}{l}1 \\
4\end{array}$ & $\begin{array}{l}90 \\
9\end{array}$ & $\begin{array}{l}<150 \\
\text { Bulk }\end{array}$ & O. & $5 \cdot 6$ & 8.14 \\
\hline $\mathrm{R}_{4}$ & 1 & 30 & $<20$ & 0. & 4.3 & $\begin{array}{l}5.200 \\
3.99\end{array}$ \\
\hline R5 & 4 & 9 & $>15$ & 0. & 4.6 & 4.38 \\
\hline $\mathrm{R} 6$ & 1 & 9 & $<15$ & 1 & 5.6 & 6 \\
\hline R7 & 1 & 9 & $>15$ & 0. & 4.3 & 3. \\
\hline R8 & 1 & 3 & $<15$ & 0. & 4.7 & 5.22 \\
\hline R9 & 4 & 9 & $<15$ & 0. & 6 & $5 \cdot 32$ \\
\hline Río & 4 & 3 & Bulk & 0. & 5.52 & 4.86 \\
\hline R11 & 4 & 90 & $<150$ & 0.1 & 6.16 & $5 \cdot 32$ \\
\hline R12 & 1 & 30 & Bulk & 0.1 & 4.57 & 4.96 \\
\hline $\mathrm{R} 13$ & 4 & 30 & $<150$ & 1 & 5.1 & 5.1 \\
\hline R14 & 4 & 9 & $<2$ & 1 & 5.14 & 3.38 \\
\hline R16 & 1 & 30 & Bulk & 1 & 4.23 & 3.58 \\
\hline $\mathrm{R} 17$ & 1 & 3 & $<2$ & o. & 4.1 & 3.16 \\
\hline R18 & 1 & 3 & $<20$ & 0. & 3.3 & 3.58 \\
\hline R19 & 1 & 3 & $>15$ & o. & 3.5 & 2.63 \\
\hline R2O & 4 & 3 & Bulk & 1 & 4.1 & 4.08 \\
\hline R21 & 4 & 9 & $<20$ & o. & 4.6 & 4.18 \\
\hline R22 & 4 & 30 & $<20$ & 1 & 4.6 & 3. \\
\hline R23 & 1 & 3 & Bulk & 0.5 & 4.73 & 4.64 \\
\hline R24 & 4 & 90 & $<2$ & 0.1 & 4.9 & 3.26 \\
\hline R25 & 4 & 3 & $>150$ & O. & 2.8 & 0.77 \\
\hline R26 & 1 & 9 & $<15$ & 0. & 6.22 & 6.4 \\
\hline R27 & 1 & 90 & Bulk & 0. & 5.41 & 6.96 \\
\hline R28 & 4 & 3 & $<150$ & 0. & 5.6 & 6.07 \\
\hline R29 & 1 & 3 & $>15$ & 0. & 2.7 & 1.21 \\
\hline $\mathrm{R} 31$ & 4 & $\begin{array}{l}9 \\
0\end{array}$ & Bulk & 1 & 6.5 & 4.99 \\
\hline
\end{tabular}

Table 6. Estimation of the factor effect.

\begin{tabular}{lcclcc}
\hline & Term & Sum square & Mean square & F-value & $\%$ \\
\hline Model & A-Pressure & 2.27669 & 2.27669 & 0.0049 & 8.68676 \\
Model & B-Temperature & 8.27049 & 8.27049 & 0.0014 & 31.5562 \\
Model & C-Particle size & 11.6495 & 3.88318 & 0.0029 & 44.449 \\
Model & D-S/L ratio & 0.533621 & 0.26681 & 0.0406 & 2.03604 \\
Model & AB & 0.00407797 & 0.00407797 & 0.6090 & 0.015559 \\
Model & AC & 0.265754 & 0.0885848 & 0.1152 & 1.01399 \\
Model & AD & 0.167835 & 0.0839177 & 0.1187 & 0.64037 \\
Model & BC & 0.547924 & 0.182641 & 0.0588 & 2.09061 \\
Model & BD & 1.14584 & 0.572918 & 0.0193 & 4.37195 \\
Model & CD & 0.300636 & 0.0601272 & 0.1657 & 1.14708 \\
Aliased & ABC & 0.52314 & 0.26157 & 0.0414 & 1.99605 \\
Aliased & ABD & 0.500634 & 0.500634 & 0.0218 & 1.91018 \\
Aliased & ACD & Alias & & & \\
Aliased & BCD & Alias & & & \\
Aliased & ABCD & Aliased & & & \\
Error & Lack Of Fit & 0 & & & 0.08623 \\
Error & Pure Error & o.0226 & & & \\
& Residuals & 0.0226 & 0.0113 & & \\
\hline
\end{tabular}


Table 7. Analysis of variance (ANOVA) for the model.

\begin{tabular}{|c|c|c|c|c|c|}
\hline Source & Sum of squares (SS) & Degrees offreedom (df) & Square & F-value & $\begin{array}{l}p- \\
\text { value }\end{array}$ \\
\hline $\begin{array}{l}\text { Model } \\
\text { A-Pressure }\end{array}$ & $\begin{array}{l}24.48 \\
0.51\end{array}$ & $\begin{array}{l}12 \\
1\end{array}$ & $\begin{array}{l}2.04 \\
0.51\end{array}$ & $\begin{array}{l}18.87 \\
4.76\end{array}$ & $\begin{array}{r}<0.000 \\
0.0444\end{array}$ \\
\hline$\overline{\mathrm{C}}$-Particlè size & 9.86 & 3 & 3.29 & 30 & $<0.000$ \\
\hline D-S/L ratio & 0.49 & 2 & 0.25 & 2.28 & 0.1342 \\
\hline $\mathrm{BC}$ & 0.54 & 3 & 0.18 & 1.66 & $0.215^{2}$ \\
\hline Lack of Fit & 1.71 & 14 & 0.12 & 10.79 & 0.0879 \\
\hline Pure Error & 0.023 & 2 & 0.011 & & \\
\hline Cor Total & 26.21 & 28 & & & \\
\hline
\end{tabular}

The sum of squares (SS) for a term is the amount of information that can be attributed to the term as it changes. ${ }^{[8]}$ The degrees of freedom (df) for a main effect is the number of levels of the factor minus one, while that for interaction is the product of the number of degrees of freedom associated with individual components of the interaction. The mean square (MS) is given by dividing SS model by df model as shown:

$$
\text { SSmodel } \div \text { dfmodel }=24.48 \div 12=2.04(1)
$$

On the other hand, the $F$-value acts as a test for comparing the model variance with residual (error) variance. Prob $>F$ is the probability value that is associated with the $F$-value for any term. It is the probability of getting an $F$-value of this size if the term did not have an effect on the response factor. A term that has a probability (Prob $>F$ ) value less than 0.05 would be considered a significant factor. A probability value greater than 0.10 is regarded as not significant. ${ }^{[8]}$ Therefore, the variables A, B, C and BD are significant model terms. A significant lack of fit means the runs replicate well and therefore their variance is small. [8]

The lack of fit should not be significant as the idea is to have a model that fits. The lack of fit value of 10.79 indicates that there is an $8.79 \%$ chance that a "lack of fit" this large can be due to noise. The model $F$-value of 18.87 implies the model is significant as there is only a $0.01 \%$ chance that a "model $F$-value" this large could occur due to noise. The residual mean square (MS) is the estimate of variance around the model. This value gives any deviation not explained by the model. In addition to ANOVA, the software generates the statistics for ANOVA which ex- plain the model behavior. This statistical analysis is given in Table 8 . 
Standard deviation is the root square of the error mean square. The quantity $\mathrm{R}^{2}$ measures the proportion of total variability in the data. 7 It is calculated as:-

$$
\mathrm{R}=\text { SSmodel } \div \text { SStotal }=24.48 \div 26.21=0.9340
$$

The value of 0.9340 obtained above (Table 8) means the model explains $93.40 \%$ of the variability obtained in the $\% \mathrm{CaCO}_{3}$. The coefficient of variation (CV) measures the unexplained or residual variability in the data as a percentage of the mean of the response variable, $\% \mathrm{CaCO}_{3}$ in this case. The adjusted $\mathrm{R}$-squared $\left(\mathrm{R}^{2} \mathrm{Adj}\right.$ ) is a statistic adjusted for the number of factors in the model relative to the number of points in the design. The adjusted $\mathrm{R}^{2}$ basically plateaus when insignificant terms are added to the model, while the $\mathrm{R}^{2}$ predicted decreases in the event of too many insignificant terms.

The predicted $\mathrm{R}^{2}$ value of 0.7833 (Table 8 ) indicates that the model can explain $78.33 \%$ of the variability in new data. Ideally the adjusted and predicted $\mathrm{R}^{2}$ values should be within 0.2 of each other. ${ }^{8]}$ This criteria is fulfilled in the current model (adjusted $\mathrm{R}^{2}$ - predicted $\mathrm{R}^{2}=0.8845-0.7833=0.1012$ ). Adequate precision measures the signal to noise ratio. A ratio greater than 4 is desirable. The design's ratio of 15.814 indicates an adequate signal hence the model can be used to navigate the design space. The predicted error sum of squares (PRESS) is a measure of how well the model will predict in a new experiment. A model with a small value of PRESS indicates that the model is likely to be a good predictor. ${ }^{7]}$ A value of 5.68 (Table 8), thus indicates that this model will be a good predictor in a new experiment.

\section{Diagnostics checking}

Diagnostics checking is analysis of both the input and out- put variables to check for outlying data points. It includes a

Table 8. Statistics for the ANOVA analysis.

\begin{tabular}{|l|l|c|}
\hline Standard deviation & 0.33 R-Squared $\left(\mathrm{R}^{2}\right)$ & 0.9340 \\
\hline Mean & 4.84 Adjusted $\mathrm{R}^{2}$ & 0.8845 \\
\hline Coentrientor vartance (C.v) \% & 6.79 Predicted $\mathrm{R}^{2}$ & 0.7033 \\
\hline PRESS & 5.68 Adequate Precision & 15.814 \\
\hline
\end{tabular}




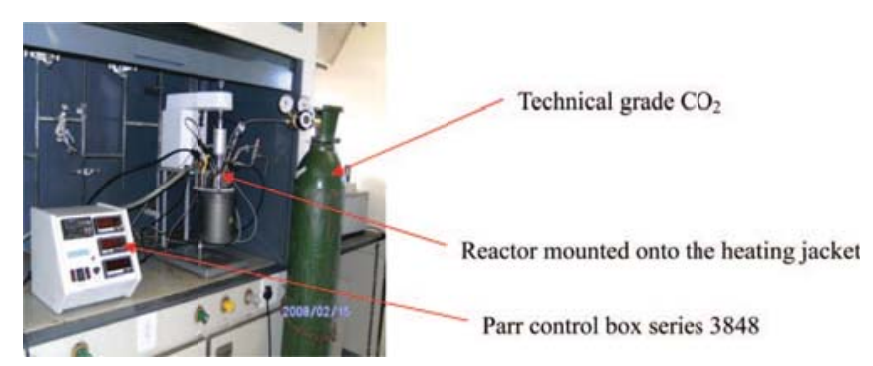

Fig. 1. Photo of the reactor used (color figure available online).

host of plots that graphically represent the data thus making it easy to identify outliers. The plots include normal probability plot(Fig. 2), residual versus predicted plot(Fig. 3), residualsversus run plot(Fig. 4), predictedversusactual plot (Fig. 5), Box-Cox plot for power transformation (Fig. 6), leverage versus run plot (Fig. 7) and the Cook's distance plot (Fig. 8). Random orientation is desired for all the plots that would imply independence of the data points. The nor- mal probability plot (Fig. 2) indicates whether the residuals follow a normal distribution in which case the points will follow a straight line. 71 Some scatter can be expected with normal data; however an "S-shaped" curve would indicate that a transformation of the response may provide a better analysis. A straight line is observed in this study, thus notransformation is required. Figures 2 to 5 are presented here.

The internally studentized residuals (Fig. 2) mean the residual has been divided by the estimated standard deviation of each particular residual. It measures the number 


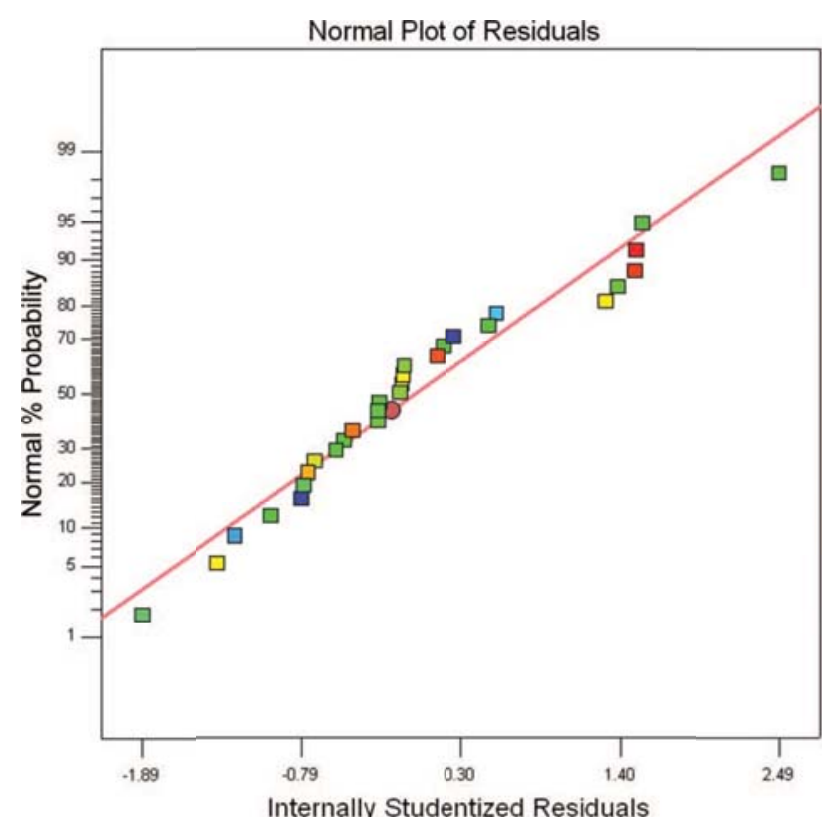

Fig. 2. Normal probability plot of residuals (color figure available online).

of standard deviations separating the actual and predicted values.

The plot of residuals versus predicted (Fig. 3) tests the assumption of constant variance. Ideally the plot should be a random scatter as is seen in Figure 3 with no definite pattern. 7 A straight line thus in this case implies that the variance is constant in the residuals. The residuals versus 


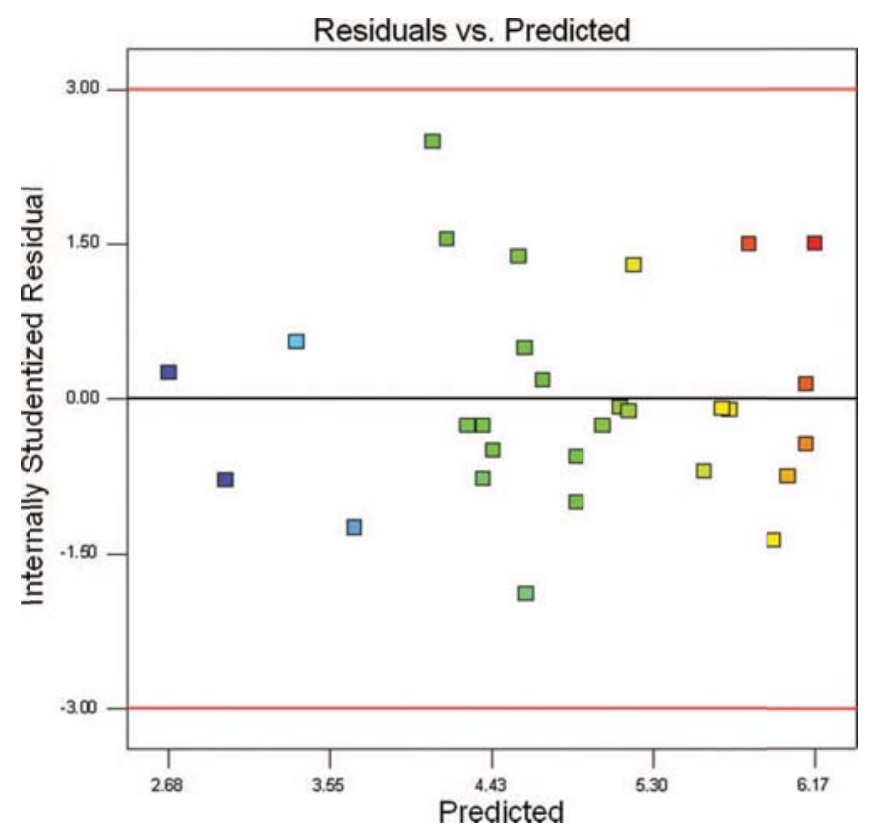

Fig. 3. Plot of residuals versus predicted (color figure available online).

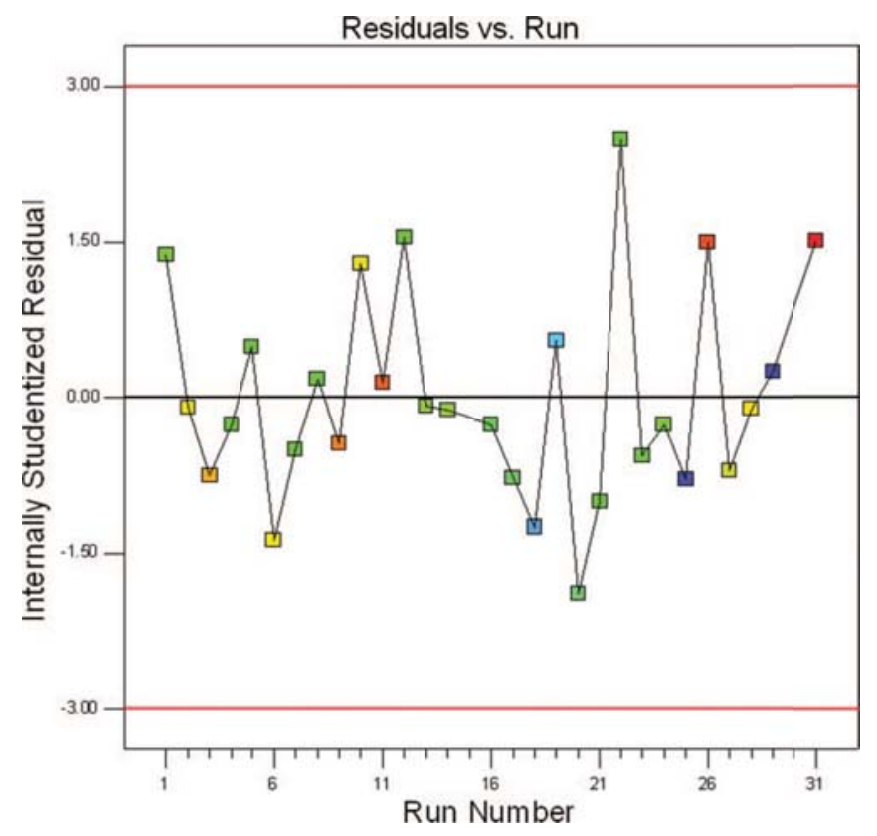

Fig. 4. Plot of residuals versus runs (color figure available online). 


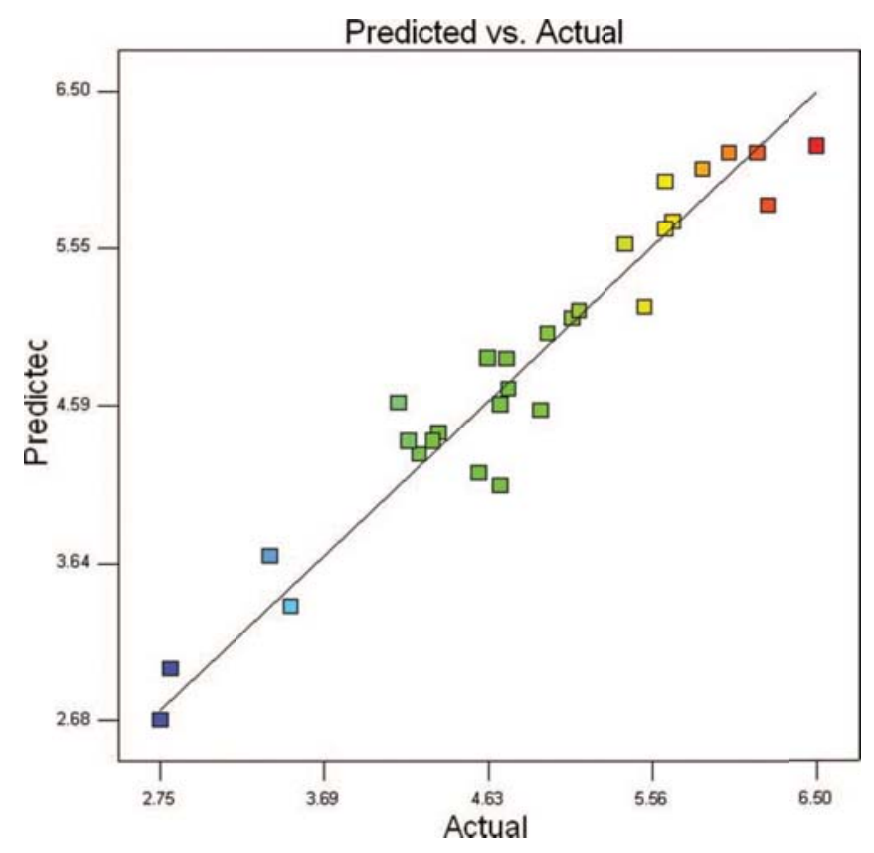

Fig. 5. Plot of predicted versus actual (color figure available online).

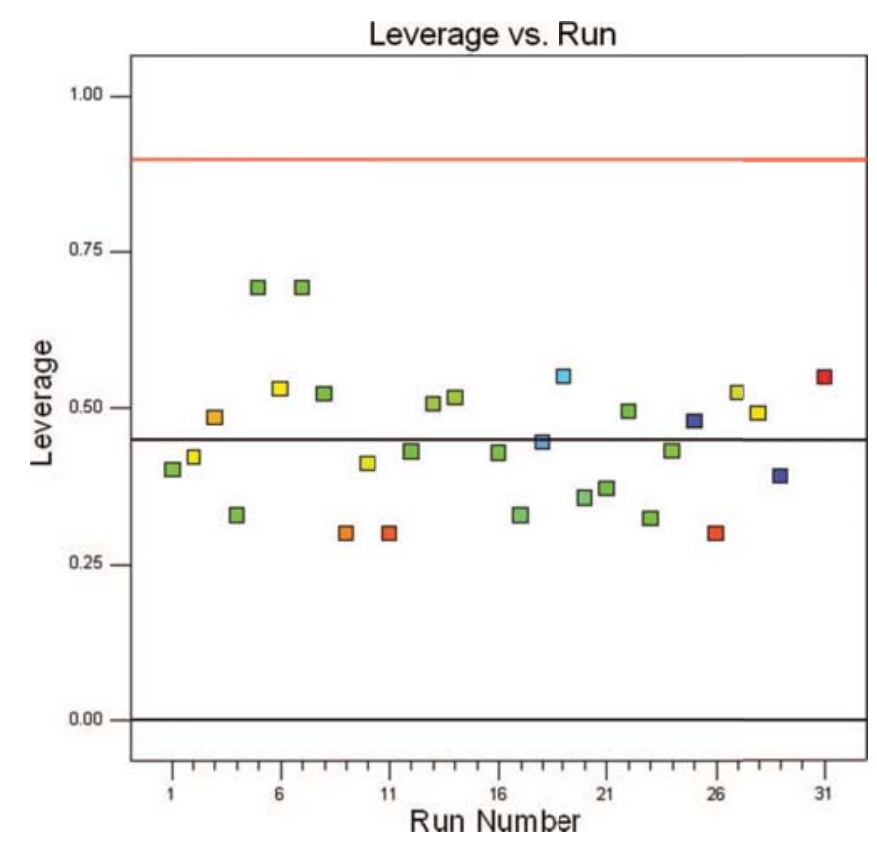

Fig. 7. Plot of leverage versus run (color figure available online).

run (Fig. 4), plots the residuals against the experimental run order. It internally checks for lurking variables that may have influenced the response factor during the experiment. The plot should also be a random scatter indicating that the residuals are random. The actual versus predicted (Fig. 5) is a graph of the actual response values versus the predicted response values. It helps to deteç a value or group of values that are not easily predicted by the model. A straight line isideal. [8]

The Box-Cox plot of power transformation was devel- oped to help in identifying the best power law transformation to apply in a model. ${ }^{[7]}$ Figure 6 shows this plot. The red lines (Fig. 
6) indicate the $95 \%$ confidence interval surrounding the lambda value. The blue line shows the current transformation, in this case it points to a value of 1 for lambda, which symbolizes the power applied to the response values $\left(\% \mathrm{CaCO}_{3}\right)$. A lambda of 1 indicates no transformation is required.[7] The green lines indicate

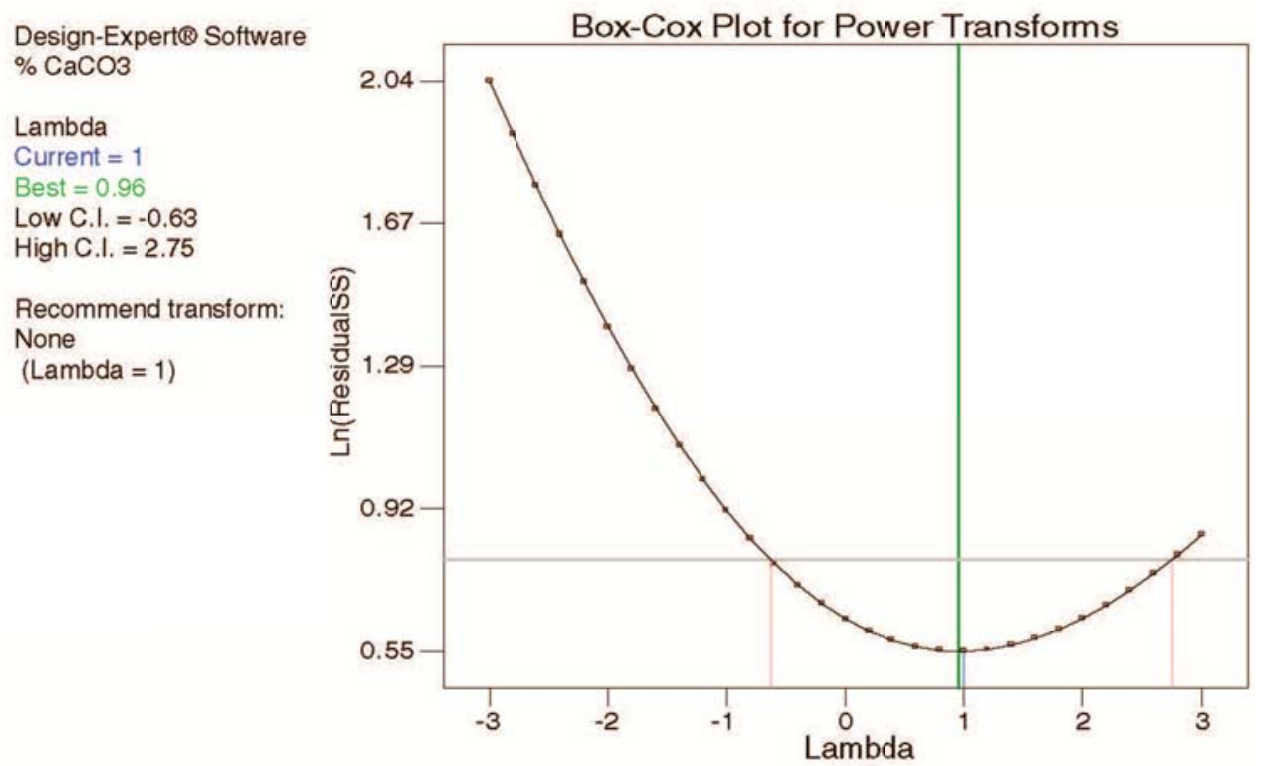

Fig. 6. Box-Cox plot for power transforms (color figure available online).

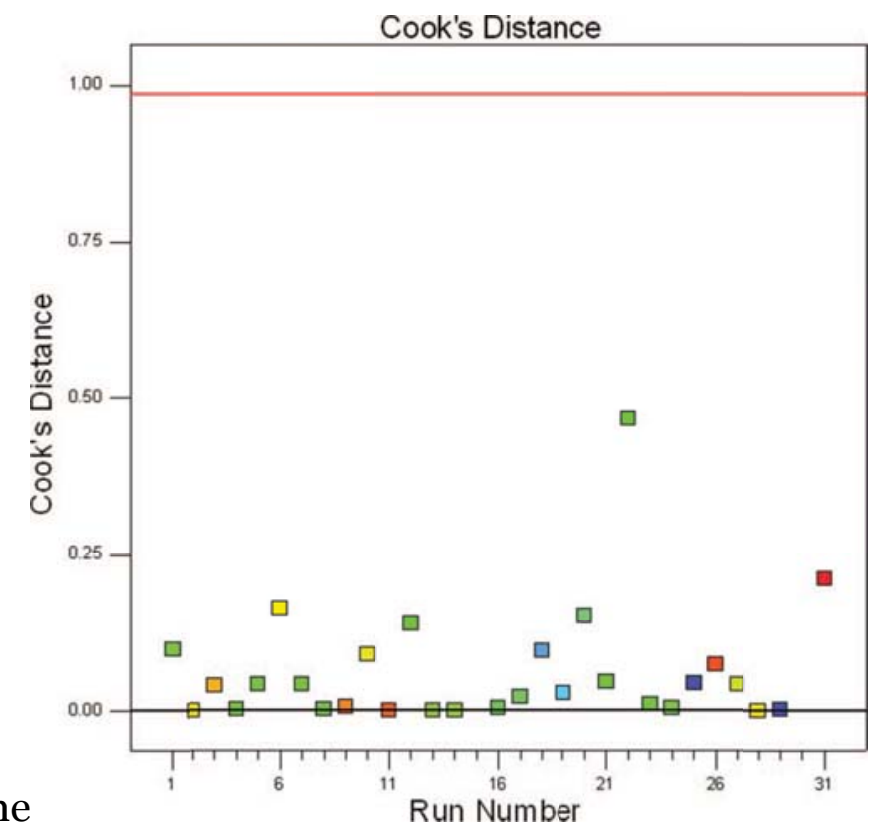


Fig. 8. Plot of Cook's distance (color figure available online).

best lambda value, in this case o.96. A recommended transformation is given based on the best lambda value. If the $95 \%$ confidence interval around the lambda value includes one, then the software does not recommend a specific transformation, as in this case.

Leverage of a point varies from $o$ to 1 and indicates how much an individual design point influences the model's predicted values. ${ }^{13]}$ A plot of leverage versus run is given in Figure 7. Leverage is a measure of how each point influences the model fit. Leverage points are those, if any, made at extreme values of the independent variables such that the lack of neighboring observations means that the fitted regression model will pass close to that particular observation. ${ }^{114}$ A leverage of 1 means the predicted value at that particular case will exactly equal the observed value of the experiment in other words the residual will be o. 7 Ideally, a clustering of points should appear close to o but definitely less than 1. In Figure 7, clustering is observed between the 0.25 and 0.75 mark, which is acceptable as all the points are below 1.

Cook's distance $(\mathrm{Di})$ is a measure of how much the regression would change if a data point is omitted from analysis or deleted. A plot of Cook's distance is given in Figure 8. Relatively large values are associated with cases with high leverage and large studentized residuals (a measure of how many standard deviations the actual value deviates from the predicted value after deleting the point in question). Cases with large $\mathrm{Di}$ relative to other cases are due to large residuals or outliers which may affect the accuracy of the outcome and regression is not guaranteed. Points with a Cook's distance of 1 or more call for closer examination. [7]

On the other hand, if the value of Cook's distance is substantially less than 1, deleting any case will not change the estimates of the regression coefficients very much. It is desired that there be strong clustering near the zero point, $[7 \mathrm{~J}$ this is observed in Figure 8. This confirms lack of outliers and all the data points are thus within range of each other. Having checked for outliers and confirmed that the residual checks were within permissible limits, the model was confirmed to be valid and could thus be confidently used to interpret the results.

\section{Interpretation of results}

Interpretation of a main effect involves comparison be- tween levels (both high and low) of a single factor e.g., temperature, averaging over levels of all the other factors (pressure, particle size and S/L ratio in this case). An interpretation of interactions on the other hand involves comparison between levels of one factor over different levels of the other factor. For instance $\mathrm{AB}(\mathrm{A}=$ pressure and $\mathrm{B}=$ temperature $)$ interaction will involve determining the behavior of pressure at all the levels of temperature and vice versa. To interpret the results, the order of interpretation should be as follows; main effects first, followed by two factor interactions, three factor interactions and so on.[5]

Generally in cases where the two factor effects and higher order interactions appear negligible, then the results of the experiment should be interpreted in terms of the main effect mean responses only, ignoring the mean responses of the combination of levels for the factors chosen. Likewise if a two factor interaction is clearly important, then the interpretation of the effects of these two factors shopld normally be based on the mean responses for the combination of levels for those two factors. ${ }^{5}$ ]

\section{Analy sis of the main effects upon carbonation}

The main effects of the variables upon the degree of carbonation in this case will be temperature, pressure, particle size and S/L ratio. From the ANOVA analysis (Table 7), one realizes that A (pressure), B (temperature) and C (particle size) main effects are significant. Factor D (S/L ratio) is not significant but it is added to make the model hierarchical. After observation of the 
behavior of the main effects with different factor combination, only the trends were chosen for presentation to reduce the amount of graphs possible.

Where different trends were observed for the same main effect, the graphs showing all the different trends will be presented. Pressure, temperature and particle size were observed to behave similarly in that their effect on the percentage of $\mathrm{CaCO}_{3}$ formed was higher at higher values. The visual interpretation is usually in the form of line graphs as shown below in Figures 9 to 13. One should look out for the effect of the input factor (be it pressure, temperature, particle size or $\mathrm{S} / \mathrm{L}$ ratio) on the $\% \mathrm{CaCO}_{3}$ as the input factor varies across the chosen levels. The Y-axis gives the $\% \mathrm{CaCO}_{3}$ for all the plots (Figs. 9-13), while the X-axis

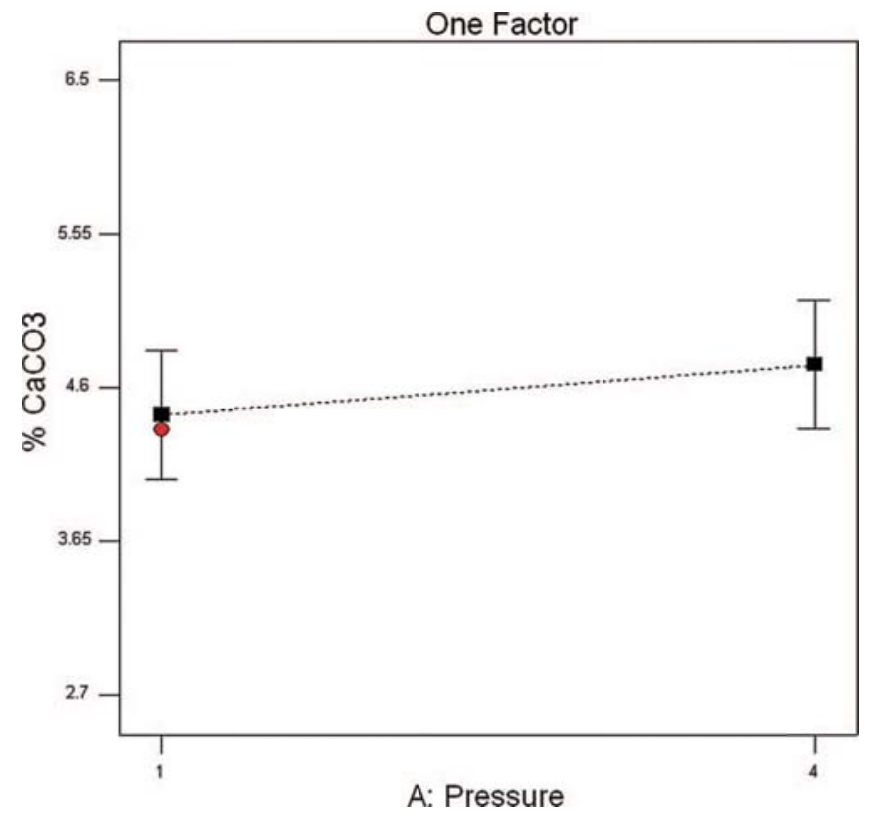


Fig. 9. Main effect of pressure for all factor combinations (color figure available online).

shows the different levels of the chosen input factor, for instance in the case of temperature the levels will be $30^{\circ} \mathrm{C}$ and $90^{\circ} \mathrm{C}$. Figure 9 represents the main effect of pressure for all factor combinations.

Variation of the other factors (i.e., temperature, particle size and S/L ratio) had the same effect on the pressure as shown above (Fig. 9). This means that at all levels of temperature, particle size and $\mathrm{S} / \mathrm{L}$ ratio, the percentage $\mathrm{CaCO}_{3}$ increased slightly as the pressure was increased from 1 Mpa to 4 Mpa. Thus, only one plot is given.

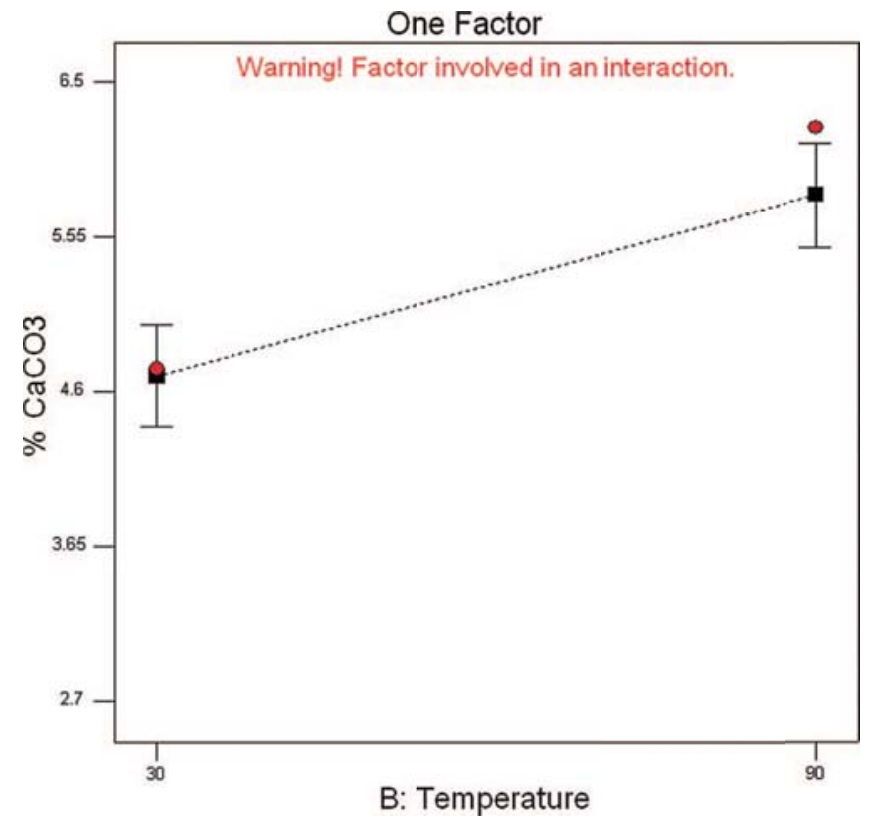

Fig. 10. Main effect of temperature for all factor combinations (color figure available online).

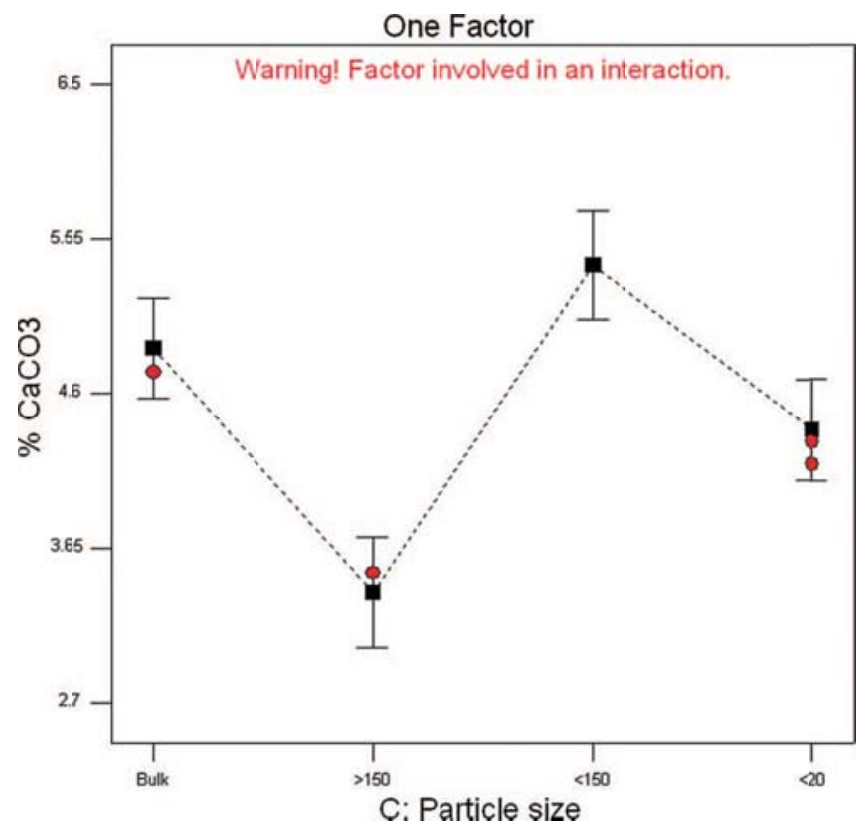


Fig. 11. Main effect of particle size for all factor combinations (color figure available online).

Pressure can therefore be said not to have a huge significance on carbonation and hence the output $\left(\% \mathrm{CaCO}_{3}\right)$. Reddy et al. $[15]$ in their studies on carbonation of alkaline FA observed that higher pressure values were not significant in the carbonation

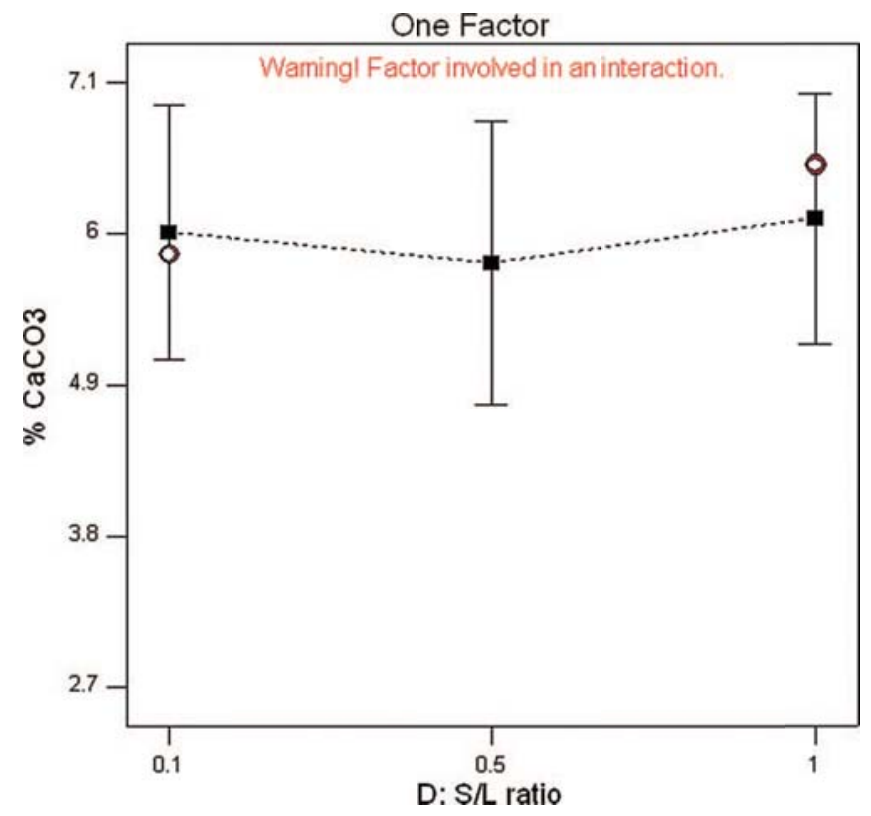

Fig. 12. Main effect of $S / L$ ratio at low temperature $\left(30^{\circ} \mathrm{C}\right)$ (color figure available online).

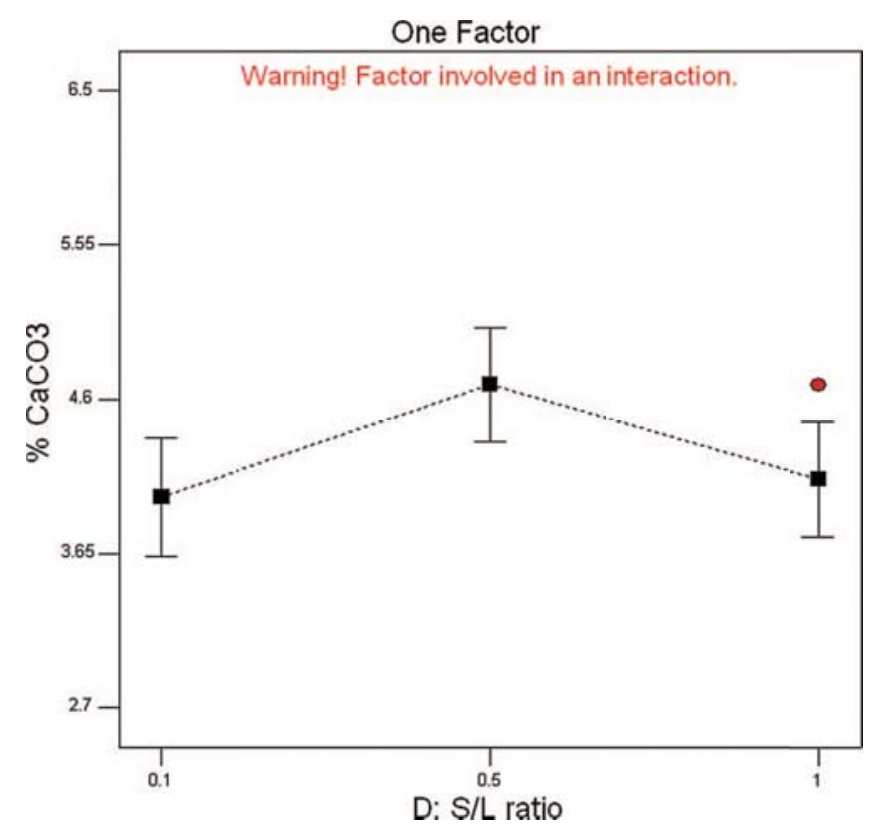

Fig. 13. Main effect of $\mathrm{S} / \mathrm{L}$ ratio at high temperature $\left(90^{\circ} \mathrm{C}\right)$ (color figure available online).

process. Rendek et al. ${ }^{[16]}$ also reported that the $\mathrm{CO}_{2}$ pressure does not affect the carbonation 
equilibrium, from a thermodynamic point of view but only influences the kinetics of the process. Other researchers $[1,17,18]$ also reported that increase in pressure does not have a high significance on the $\% \mathrm{CaCO}_{3}$ formation. This study is thus in agreement with what has been proposed in literature. Figures 10 to 13 follow next, giving the various factor combinations.

One observes that in Figures 10 to 13, a warning is displayed on the graphs. This is generated by the software to inform one that the main effect being investigated is also involved in an interaction. Caution is thus called for when interpreting the main effects, as some of them are involved in interactions as displayed in the warning signs above some graphs. One therefore needs to look at the interactions to make a comprehensive conclusion about the contribution of the effect of a particular factor towards the formation of $\mathrm{CaCO}_{3}$ through carbonation.

Figure 10 shows the effect of temperature on the amount of $\mathrm{CaCO}_{3}$ formed during carbonation. It is clear that as the temperature increases from $30^{\circ} \mathrm{C}$ to $90^{\circ} \mathrm{C}$, the percent- age of $\mathrm{CaCO}_{3}$ formed increases considerably. This signifies the importance of temperature in the carbonation process. Li et al. $[19]$ reported a similar observation and concluded that high temperatures improve the reaction kinetics hence increasing the carbonation efficiency.

In Figure 11 the effect of particle size on the formation of $\mathrm{CaCO}_{3}$ is given. Four particle sizes were considered, i.e., bulk ash, $>150 \mu \mathrm{m}, 20 \mu \mathrm{m}-150 \mu \mathrm{m}$ and the $<20 \mu \mathrm{m}$ fractions. The 20 $\mu \mathrm{m}-150 \mu \mathrm{m}$ fraction is observed to have the highest effect on the \% $\mathrm{CaCO}_{3}$. The bulk ash has the next highest contribution to $\% \mathrm{CaCO}_{3}$ formation followed by the $<20 \mu \mathrm{m}$ fraction. The $>150$ $\mu \mathrm{m}$ fraction however, is the least favourable for carbonation as it led to the lowest

$\% \mathrm{CaCO}_{3}$ output (Fig. 11).

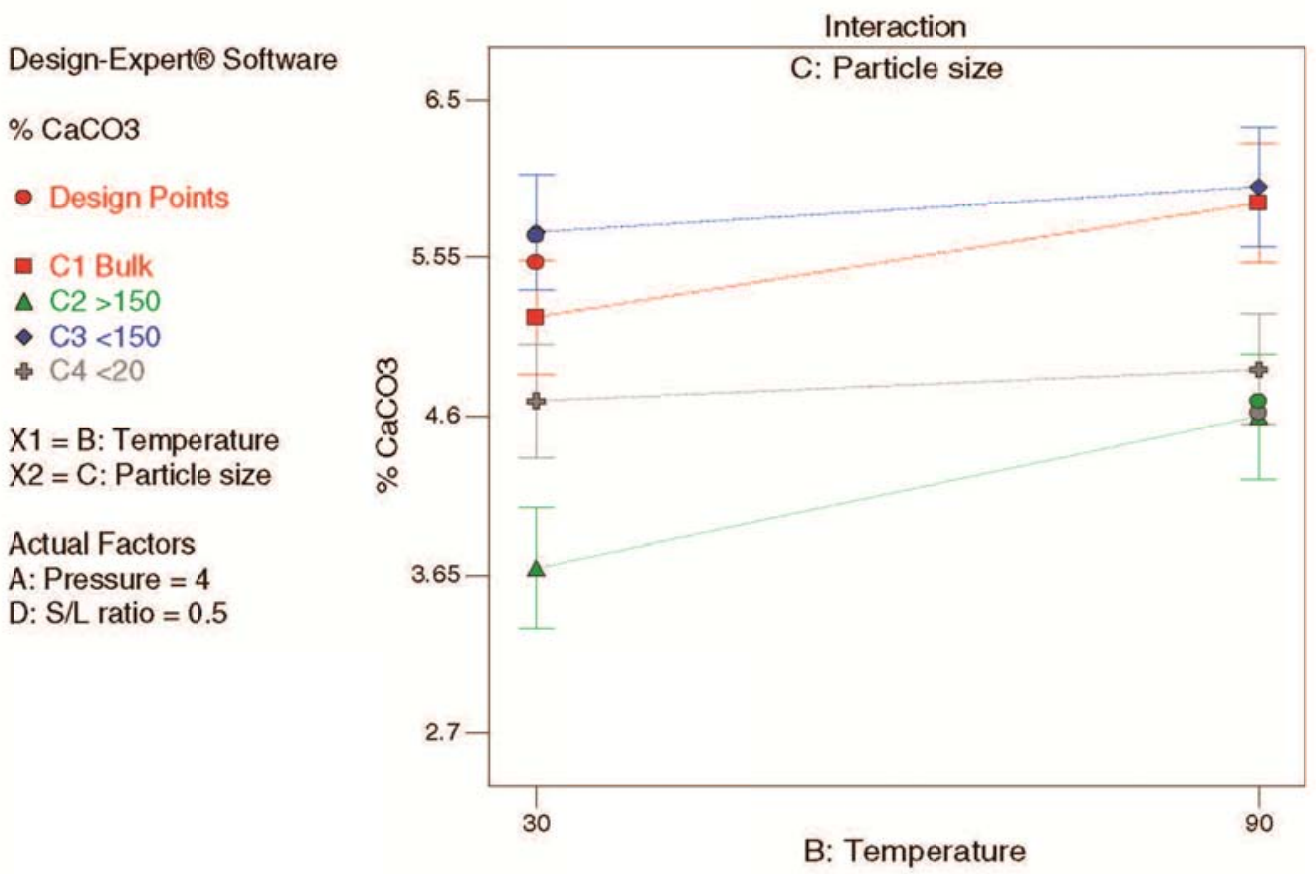

Fig. 14. Interaction effect of $\mathrm{BC}$ for all factor combinations $(<150$ represent the $20 \mu \mathrm{m}-150$ $\mu \mathrm{m}$ particle size range) (color figure available online). 


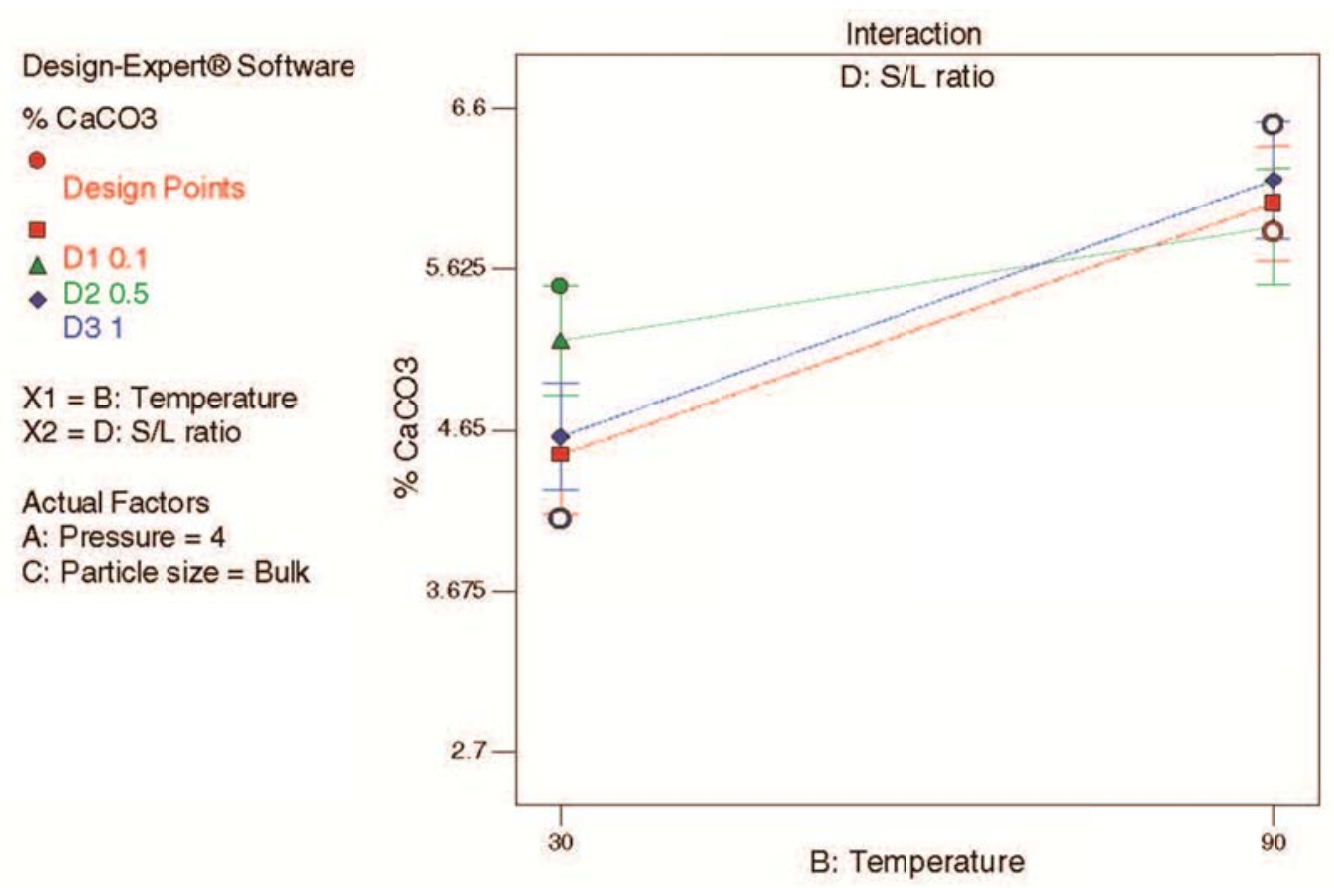

Fig. 15. Interaction effect of BD for all factor combinations (color figure available online).

These observations correlate with the XRF analysis done on the un-carbonated FA (Table 2) where it was observed that the $20 \mu \mathrm{m}-150 \mu \mathrm{m}$ particle size range had the highest $\mathrm{CaO}$ (averaging at $9.3 \%$ ), while the $>150 \mu \mathrm{m}$ particle size fraction had the lowest $\mathrm{CaO}$ of $5.894 \%$. $\mathrm{CaO}$ in the $\mathrm{FA}$ is the main source of the $\mathrm{Ca}^{2+}$ though the $\mathrm{Ca}^{2+}$ in brine also contributes towards the total $\mathrm{Ca}$ cations available for carbonation. Evaluated the effect of particle size in the carbonation of municipal solid waste incinerator (MSWI) ash and observed that carbonation was higher with smaller particle sizes. They attributed this observation to the higher $\mathrm{CaO}$ content of the smaller particle sizes, homogeneity of the particle sizes as well as the higher surface area of these particles.

Figures 12 and 13 give the effect of S/L ratio at low and high temperature respectively. At low temperatures $\left(30^{\circ} \mathrm{C}\right)$, a $\mathrm{S} / \mathrm{L}$ ratio of 1 gave a higher amount of $\mathrm{CaCO}_{3}$ arising due to carbonation (Fig. 12). On the other hand, at high temperatures $\left(90^{\circ} \mathrm{C}\right)$ the $\mathrm{S} / \mathrm{L}$ ratio of 0.5 gave the highest \% $\mathrm{CaCO}_{3}$ formation compared to a $\mathrm{S} / \mathrm{L}$ ratio of 0.1 or 1 (Fig. 13). This implies that the $\mathrm{S} / \mathrm{L}$ ratio is temperature dependent. A low $\mathrm{S} / \mathrm{L}$ ratio and high temperature will lead to higher carbonation efficiency as will a high $\mathrm{S} / \mathrm{L}$ ratio at low temperature. This would be attributed to the increased kinetics at high temperatures, hence low $\mathrm{S} / \mathrm{L}$ ratio will suffice and vice versa. Li et al.[19] in their study on the effect of S/L ratio on the carbonation of MSWI ash obtained an optimum value of 3 .

According to them, as water is the medium of dissolution, ionization and transportation of $\mathrm{CO}_{2}$, very low or very high liquid ratios will retard the reaction. Hydration and dissolution of $\mathrm{CO}_{2}$ occurs in the presence of water as well as the dissolution of $\mathrm{Ca}^{2+}$ ions from the solid phase which reacts with the carbonate ions to form $\mathrm{CaCO}_{3}$. In low $\mathrm{S} / \mathrm{L}$ ratios, the gas permeability is high and the gas can effectively diffuse into the material. Increase of the liquid content seals off the pores in the ash thus inhibiting the reaction. [19]

\section{Interpretation of interactions between the input factors}

A factor interaction is the variation between the mean for different levels of one factor over different levels of the other factor Two factor interactions should be examined first, then three factor interactions and so on. ${ }^{[5]}$ The reader is reminded that only BC (temperature and particle size in- teraction) and $\mathrm{BD}$ (temperature and S/L ratio interaction) factor interactions were found to be significant (Table 6). Only general trends are reported here in order to reduce 
the number of graphs to be discussed. Observation of the $\mathrm{BC}$ interaction at all the levels of the different factors yielded a similar trend that is presented by Figure 14.

The "I-beam" symbols on the plot given in Figure 14 depict the $95 \%$ least significant difference (LSD) interval for the plotted points. ${ }^{8]}$ The points that have non-overlapping intervals are significantly different. In other words if the lines describing the simple main effects are not parallel, then the possibility of an interaction exists. As can be seen in Figure 14, the lines for $20 \mu \mathrm{m}-150 \mu \mathrm{m}$ and the $<20 \mu \mathrm{m}$ (blue and grey lines, respectively) are almost parallel and straight. However, the lines for bulk ash and $>150 \mu \mathrm{m}$ fraction (red line and green line, respectively) show an increasing $\% \mathrm{CaCO}_{3}$ with increasing temperature.

In other words, high temperatures are recommended for these two larger particle fractions while on the other hand temperature will have little effect on the smaller particle size fraction, i.e., the $20 \mu \mathrm{m}-150 \mu \mathrm{m}$ and $<20 \mu \mathrm{m}$ fractions. Hence for effective carbonation without high energy inputs, it would be necessary to use the smaller size fractions of FA. The interaction of temperature and $\mathrm{S} / \mathrm{L}$ ratio (BD interaction) investigates the effect of the different temperatures at each $\mathrm{S} / \mathrm{L}$ employed and is given in Figure 15.

Overlapping of the lines on the high temperature side depicts lack of interaction between temperature and all the $\mathrm{S} / \mathrm{L}$ ratios used. This is due to the fact that only the points that have non-overlapping intervals are significantly different, but in Figure 15 all the S/L ratios overlap at the high temperature $\left(90^{\circ} \mathrm{C}\right)$. However one observes that on the lower temperature side $\left(30^{\circ} \mathrm{C}\right), \mathrm{S} / \mathrm{L}$ ratio of 0.1 and 0.5 interact with temperature. The 0.5 ratio will however give a higher $\% \mathrm{CaCO}_{3}$. This is contrary to what was observed in Figures 12 and 13, where a $\mathrm{S} / \mathrm{L}$ ratio of 1 was observed to have a higher effect on the amount of $\mathrm{CaCO}_{3}$ at $30{ }^{\circ} \mathrm{C}$ and a S/L ratio of 0.5 optimum at $90^{\circ} \mathrm{C}$. As it had been pointed out earlier, main effects that are involved in interactions cannot be relied upon solely to investigate their effect on the carbonation efficiency. The interaction plots are more robust and hence one would therefore consider experimenting at low temperature using a S/L ratio of 0.5 , i.e., relying on the interaction plots.

\section{Conclusions}

Run R31 carried out at $4 \mathrm{Mpa}, 90^{\circ} \mathrm{C}$, using bulk ash and a S/L ratio of 1 gave the highest percentage $\mathrm{CaCO}_{3}$ yield $(6.5 \%)$ as determined by chittick tests while quantitative XRD gave Run R2 conducted at $1 \mathrm{Mpa}, 90^{\circ} \mathrm{C}$, using the $20 \mu \mathrm{m}-150 \mu \mathrm{m}$ particle size range at a S/L ratio of 0.5 as the one with highest \% $\mathrm{CaCO}_{3}(8.14 \%)$. ANOVA analysis, gave the main effects of pressure, temperature and particle size as significant together with the interactions of temperature and S/L ratio as well as the interaction of temperature and particle size. The model was found to be statistically significant and could explain $93.40 \%$ of the variability in the percentage of $\mathrm{CaCO}_{3}$ data. Diagnostic plots were observed to follow the ideal situation. Pressure had a slight influence on the percentage of $\mathrm{CaCO}_{3}$, while the effect of temperature was pronounced. The particle size range of $20 \mu \mathrm{m}-150 \mu \mathrm{m}$ enhanced the degree of carbonation that could be achieved. This was closely followed by the bulk ash while the $>150 \mu \mathrm{m}$ particle fraction had the least influence on the $\% \mathrm{CaCO}_{3}$. The effect of $\mathrm{S} / \mathrm{L}$ ratio was temperature dependent. At low temperature a S/L ratio of 1 resulted in the highest percentage $\mathrm{CaCO}_{3}$ formation. On the other hand at high temperature, the ratio of 0.5 resulted in the highest percentage $\mathrm{CaCO}_{3}$ formation. The temperature dependence of the $\mathrm{S} / \mathrm{L}$ ratio could also be explained in terms of the higher percentage contribution value observed for the temperature-particle size interaction. In the temperature- particle size interaction, both the bulk ash and the $>150 \mu \mathrm{m}$ fractions gave higher values of percentage of $\mathrm{CaCO}_{3}$ formation at high temperature. Overall the two most important parameters in the carbonation of FA and brine were found to be particle size and temperature.

Other studies have shown the importance of temperature in carbonation of either MSWI ash or FA, while pressure has been shown to be an insignificant variable. The observations in this study using South African class F ash thus confirm the literature observations. The effect of particle size was observed to be highest at smaller particle sizes due to the higher surface area to volume ratio hence better contact. For the S/L ratio, very low or very high values were observed to inhibit carbonation. High temperatures were shown to favor carbonation reactions as the reaction kinetics were enhanced while the particle size range of 20 
$\mu \mathrm{m}-150 \mu \mathrm{m}$ was found to enhance carbonation. On average, this particle size range had a $\mathrm{CaO}$ content of $9.3 \%$, compared to the bulk ash's CaO content of $9.198 \%$, further confirming that $\mathrm{CaO}$ was enriched in the smaller ash particles fraction.

The application of statistical design in carrying out the experiments resulted in a clear understanding of the effect of the applied input factors. Two main advantages were achieved using this statistical approach; first, the number of experimental combinations was greatly reduced compared to studying the factors one at a time. Considering the same cost and time expenditure, the statistical approach was found to be robust in generating the desired data. Secondly, it was possible to investigate the effect of each factor as well as the arising interactions, which would not have been possible with one factor at a time approach.

\section{Acknowledgments}

The authors acknowledge Dr. Patrick Ndung'u for his assistance as well as Eskom and Sasol for funding this study. 


\section{References}

[1] Montes-Hernandez, G.; Pé rez-Ló pez, R.; Renard, F.; Nieto, J.M.; Charlet, L. Mineral sequestration of $\mathrm{CO}_{2}$ by aqueous carbonation of coal combustion fly-ash. J. Hazard. Mater. 2009, 161(2-3), 1347-1354.

[2] Figueroa, D.J.; Fout, T.; Plasynki, S.; McIlvried, H.; Srivastava, D.R. Advances in $\mathrm{CO}_{2}$ capture technology, The US Department of Energy's carbon sequestration program. Inter. J. Greenhouse Gas Cntrl. 2008, 2, 9-20.

[3] Wolf, H.G.; Chizmeshya, A.V.G.; Diefenbacher, J.; McKelvy, J.M. In Situ observation of $\mathrm{CO}_{2}$ sequestration reaction using a novel micro reaction system. Environ. Sci. Technol. 2004, 38(3), 932-936.

[4] Eskom Environmental Report. Reducing water consumption, 2006. http://eskom.co.za

[5] Mead, R. The Design of Experiments-Statistical Principles for Practical Application. Cambridge University Press, New York, 1991.

[6] Shi, Y.L.; Jun-Qing, Q.; Zhang-Gui, W.; Wei-Dong, Y.; Guo-Feng, W.; Yi-Bin, P.; Kai, Y.Z. Application of statistical method to evaluate immobilization variables of trypsin entrapped with sol-gel method. J. Biochem. Technol. 2009, 1(3), 79-84.

[7] Montgomery, D.C. Design and Analysis of Experiments, 7th edition, John Wiley and Sons Inc., New Jersey, 2009.

[8] Design-Expert 7.1 User's manual guide, Factorial designs tutorial DX7-03A, Revised on 15th April 2007.

[9] American Society for Testing and Materials, ASTM 618: Standard speciation for fly ash and raw or calcined natural pozzolan for uses as a mineral admixture in Portland cement concrete, American Society for Testing and Materials, Philadelphia, Pennsylvania, 1993.

[10] Enders, M. The $\mathrm{CaO}$ distribution to mineral phases in a high cal- cium fly ash from Eastern Germany. Cement Concrete Res. 1996, 26(2), 243-251.

[11] Petrik, L.; Lewis, A.E.; Hendry, B.A. Brine treatment and disposal. Coaltech Report, Pretoria, South Africa, 2007.

[12] Muriithi, G.N.; Gitari, W.M.; Petrik, L.F.; Ndungu, P.G. Carbonation of brine impacted coal fly ash: Implications for $\mathrm{CO}_{2}$ sequestration. J. Environ. Mgmt. 2011, 92, 655-664.

[13] Virgil, L.A.; McLean, A.R. Design of Experiments; A Realistic Ap-proach. Marcel Dekker Inc., New York; 1974.

[14] Everitt, B.S. Cambridge Dictionary of Statistics, Cambridge Uni- versity Press, ISBN o521-81099; 2002.

[15] Reddy, K.J.; Gloss, S.P.; Wang, L. Reaction of $\mathrm{CO}_{2}$ with alkaline solid wastes to reduce contaminant mobility. Water Resour. 1994, 28(6), 1377-1382.

[16] Rendek, E.; Ducom, G.; Germain, P. Influence of organic mat- ter on municipal solid waste incineration bottom ash carbonation. Chemosphere 2006, 64, 1212-1218. 
[17] Soong, Y.; Goodman, A.L.; McCarthy-Jones, J.R.; Baltrus, J.P. Experimental and simulation studies on mineral trapping of $\mathrm{CO}_{2}$ with brine. Energy Conserv. Mgmt. 2004, $45,1845-1859$.

[18] Chiquet, P.; Daridon, J.; Broseta, D.; Thibeau, S. CO $2 /$ water interfacial tensions under pressure and temperature conditions of $\mathrm{CO}_{2}$ geological storage. Energy Conver. Mgmt. 2007, 48, 736-744.

[19] Li, X.; Bertos, F.M.; Hills, D.C.; Carey, J.P. \& Simon, S. Accelerated carbonation of municipal solid waste incineration fly ashes. Waste Mgmt. 2007, 27, 1200-1206. 